PREPARED FOR THE U.S. DEPARTMENT OF ENERGY, UNDER CONTRACT DE-AC02-76CH03073

PPPL-3902

PPPL-3902

UC-70

Lithium Pellet Injector Development for NSTX

by

G. Gettelfinger, J. Dong, R. Gernhardt, H. Kugel,

P. Sichta, and J. Timberlake

November 2003

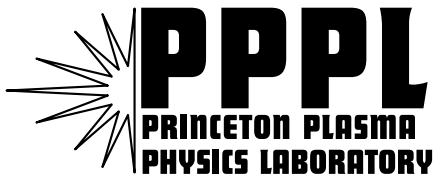

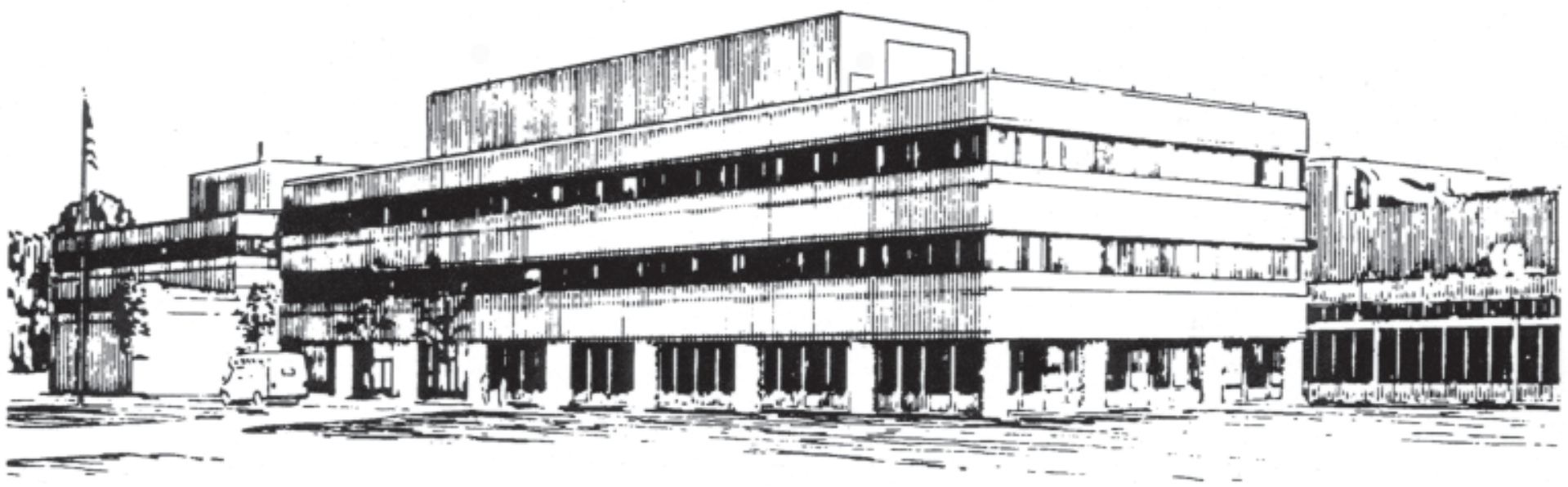

PRINCETON PLASMA PHYSICS LABORATORY PRINCETON UNIVERSITY, PRINCETON, NEW JERSEY 


\section{PPPL Reports Disclaimer}

This report was prepared as an account of work sponsored by an agency of the United States Government. Neither the United States Government nor any agency thereof, nor any of their employees, makes any warranty, express or implied, or assumes any legal liability or responsibility for the accuracy, completeness, or usefulness of any information, apparatus, product, or process disclosed, or represents that its use would not infringe privately owned rights. Reference herein to any specific commercial product, process, or service by trade name, trademark, manufacturer, or otherwise, does not necessarily constitute or imply its endorsement, recommendation, or favoring by the United States Government or any agency thereof. The views and opinions of authors expressed herein do not necessarily state or reflect those of the United States Government or any agency thereof.

\section{Availability}

This report is posted on the U.S. Department of Energy's Princeton Plasma Physics Laboratory Publications and Reports web site in Fiscal Year 2004. The home page for PPPL Reports and Publications is: http://www.pppl.gov/pub_report/

DOE and DOE Contractors can obtain copies of this report from:

U.S. Department of Energy

Office of Scientific and Technical Information

DOE Technical Information Services (DTIS)

P.O. Box 62

Oak Ridge, TN 37831

Telephone: (865) 576-8401

Fax: (865) 576-5728

Email: reports@adonis.osti.gov

This report is available to the general public from:

National Technical Information Service

U.S. Department of Commerce

5285 Port Royal Road

Springfield, VA 22161

Telephone: $1-800-553-6847$ or

(703) $605-6000$

Fax: (703) 321-8547

Internet: http://www.ntis.gov/ordering.htm 


\title{
Lithium Pellet Injector Development for NSTX
}

\author{
G. Gettelfinger, J. Dong, R.Gernhardt, H. Kugel, P. Sichta, J. Timberlake \\ Princeton Plasma Physics Laboratory, Princeton, NJ 08543, USA \\ ggettelf@pppl.gov
}

\begin{abstract}
A pellet injector suitable for the injection of lithium and other low- $Z$ pellets of varying mass into plasmas at precise velocities from 5 to $500 \mathrm{~m} / \mathrm{s}$ is being developed for use on NSTX. The ability to inject low-Z impurities will significantly expand NSTX experimental capability for a broad range of diagnostic and operational applications. The architecture employs a pellet-carrying cartridge propelled through a guide tube by deuterium gas. Abrupt deceleration of the cartridge at the end of the guide tube results in the pellet continuing along its intended path, thereby giving controlled reproducible velocities for a variety of pellets materials and a reduced gas load to the torus. The planned injector assembly has four hundred guide tubes contained in a rotating magazine with eight tubes provided for injection into plasmas. A PC-based control system is being developed as well and will be described elsewhere in these Proceedings. The development path and mechanical performance of the injector will be described.
\end{abstract}

\section{INTRODUCTION}

The National Spherical Torus Experiment (NSTX), located at the Princeton Plasma Physics Laboratory, is evaluating the physics principles of a spherical torus (ST) geometry and has been extensively described elsewhere [1]. The NSTX research plan calls for the capability to inject small solid or micro pellet ensembles of lithium, and other low-Z impurities for operational and diagnostic applications. These include 1) wall conditioning, 2) measuring edge impurity transport, 3) inducing edge transport barriers, 4) measuring $\mathrm{q}(\mathrm{r})$ profiles, 5) probing edge flows and rotation, 6) enhancing charge exchange signals, 7) controlling disruption decay rate, and 8) lithium limiter simulation. Garzotti, et al., have described a pneumatic injector using a shuttling cartridge to convey a pellet to its launch point[2]. This effort served as a solid starting point for the NSTX injector development path.

\section{PROTOTYPE EFFORTS}

Figure 1 shows the output end of the single guide tube injection assembly used to qualify the concept of

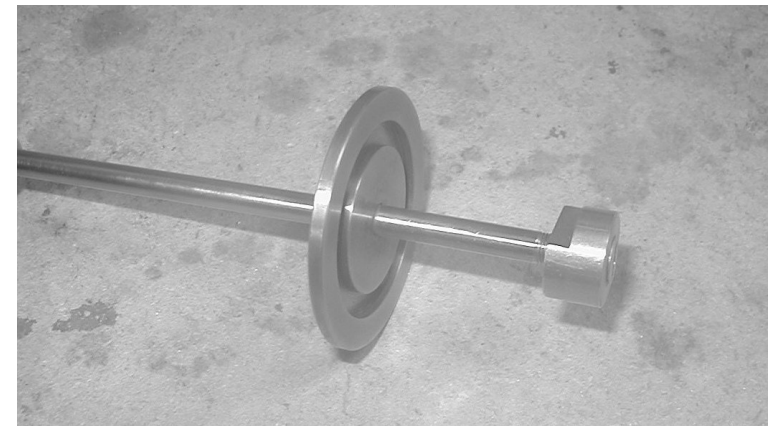

Figure.1. Prototype Single Guide Tube injector.

a pneumatically driven, pellet-bearing cartridge being abruptly decelerated at the end of its translation. The guide tube is of AISI 304 stainless steel seamless tubing having an outside diameter of 0.250 inches and a wall thickness of about 0.035 . A 0.182 inch reamer was applied to each twelve-inch long guide tube to assure a consistent bore. An ISO(KF) 40 vacuum interface flange was selected to facilitate the frequent demounting associated with the reloading of the injector after each shot. A final and important feature of the prototype injector is the cartridge stop subassembly (the "stop") at the output end. The stop has an internal female thread that screws onto the male threaded OD of the guide tube. The opposite end of the stop has a removable, screwed plug with two significant features. First, the plug has an exit bore of 0.125 inches and, secondly, the plug holds a flat washer-shaped Viton seal with a similar bore inside the stop. When the stop is threaded onto the guide tube, the faced-off end of the tube contacts against the Viton seal. This sealing contact becomes a significant gas limiting feature.

Figures $2 \mathrm{a} \& 2 \mathrm{~b}$ show the details of a typical Vespel grade SP-1 polyimide cartridge. The 0.180 inch outside diameter of the cartridge complements the 0.182 bore of the guide tube to yield a low clearance sliding fit. Polyimide was selected both because sliding friction in the guide tube was expected to be minimal and because "sticky" substances such as lithium are expected to free themselves easily from the cartridge during launch/cartridge deceleration. 

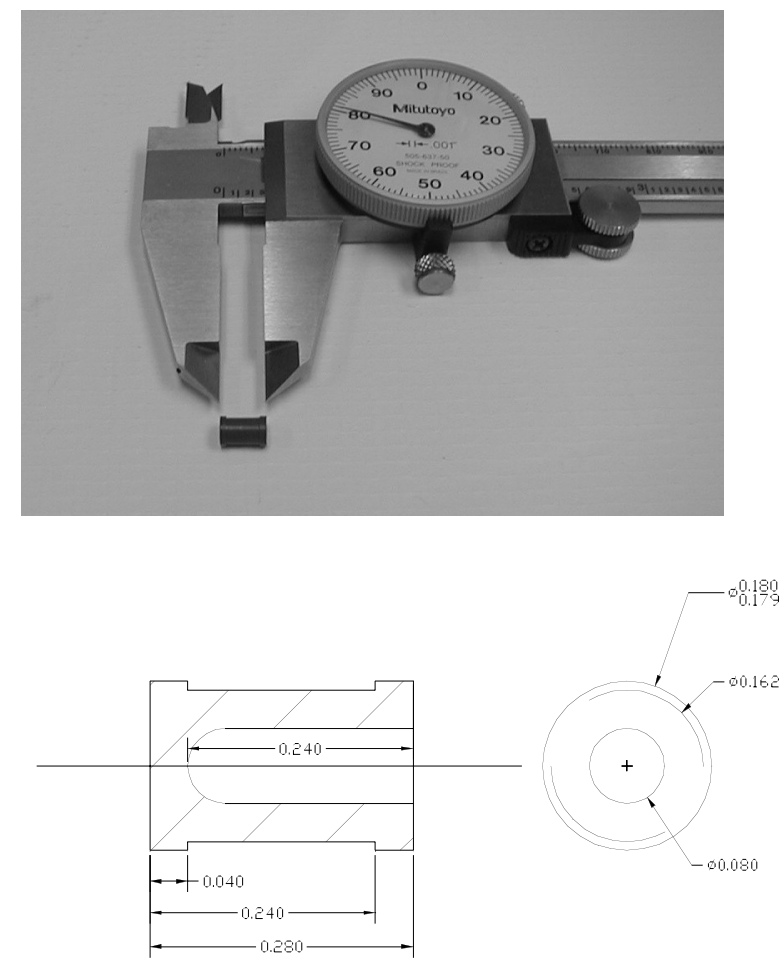

Figures2a \& 2b. Vespel Polyimide Cartridge.

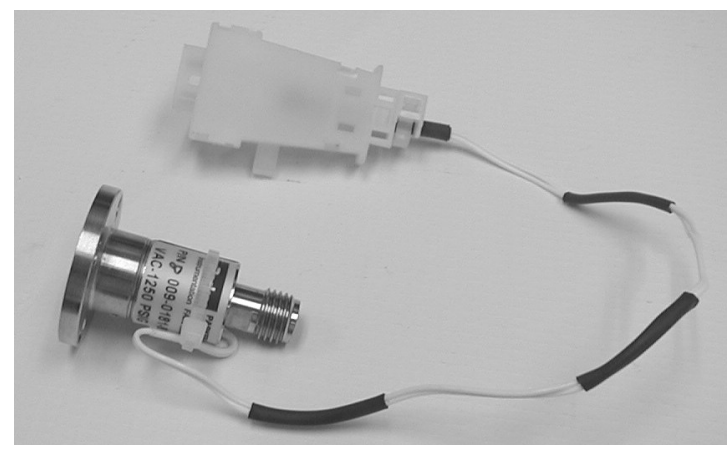

Figure 3. Parker Series 9 Valve.

The Viton seal contained in the stop and described above serves as the contacting element that absorbs the energy of cartridge deceleration and tends to seal the volume of the guide tube bore from the downstream target vacuum system. This "seal" has such a low conductance to the target chamber that the eventual pressure rise in the target chamber from delayed admission of propellant gas occurs mostly after an NSTX plasma has terminated.

Figure 3 shows a Parker Hannifin Series 9 solenoid-operated valve used during the prototype investigation. The valve has the combined attributes of small size (1.06 inch flange OD) and quick response. Valve opening time can be as little as 180 microseconds giving researchers and operations personnel fine control over propellant drive.

Figure 4 shows traces archived from a particular pellet flight. The first trace shows the output from the valve controller energizing the valve for $8 \mathrm{~ms}$. The second trace shows the response of the piezoelectric element mounted on the valve suggesting the cartridge encountered the stop at 9.5 ms. The third trace in Figure 4 shows the
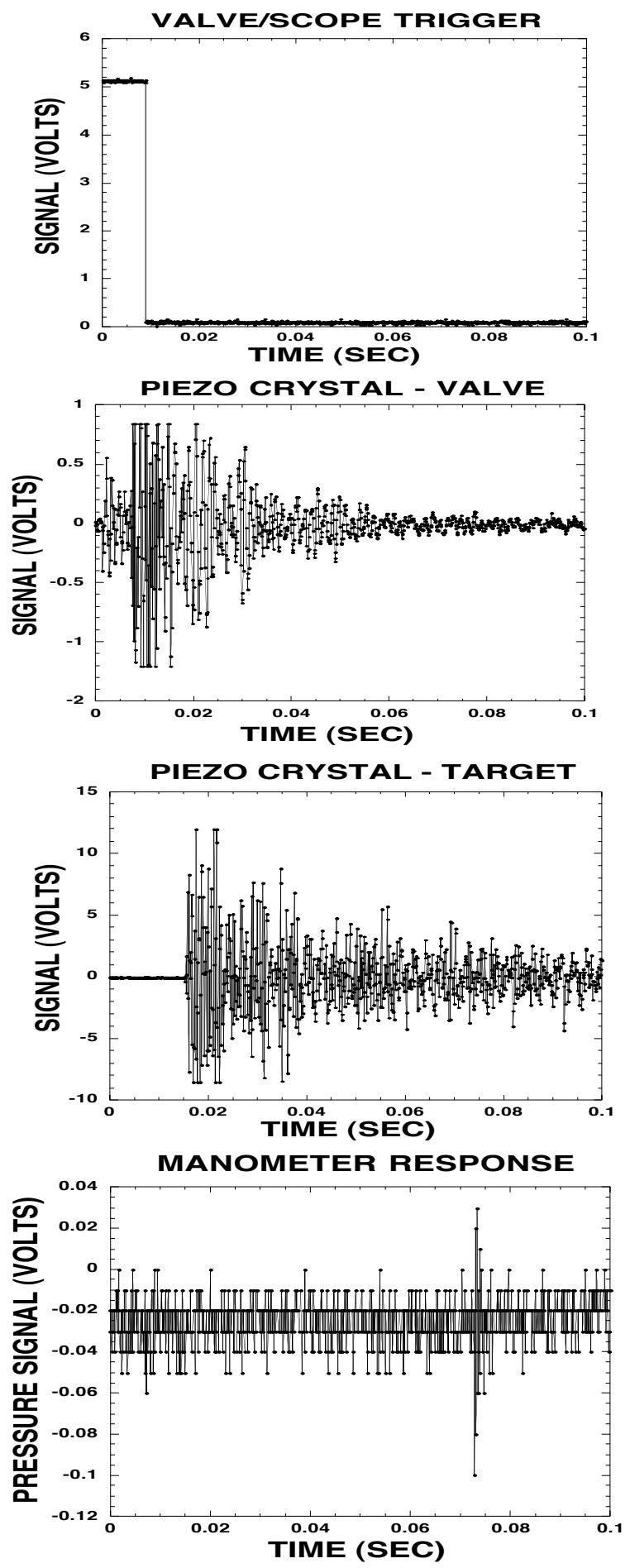

Figure 4. Typical Prototype Pellet Event. 
0.03 inch diameter by approximately 0.08 inch-long aluminum pellet arriving at the piezoelectricallymonitored target about $16 \mathrm{~ms}$ into the trial. Given a distance from the stop to the target of about 0.66 meters, an average velocity of $94 \mathrm{~m} / \mathrm{s}$ is calculated. The fourth trace in Figure 4 shows the first response of the capacitance manometer measuring the target chamber pressure occurring at $72 \mathrm{~ms}$. Total best-case gas loads of 5 Torr-liters have been observed. Launching pellets into plasmas later than $\mathrm{t}=0$ seconds will lessen the contribution of deuterium gas through this avenue.

\section{COMPLETE INJECTOR ASSEMBLY}

Figure 5 shows a depiction of the now-fabricated pellet injector with 400 guide tubes mounted in a rotating magazine having 50 zones of 8 tubes; each on a radial line. The magazine is suspended in a main vacuum chamber and rotated by a drive including a stepper motor, encoder, and a bellowssealed rotary feedthrough.

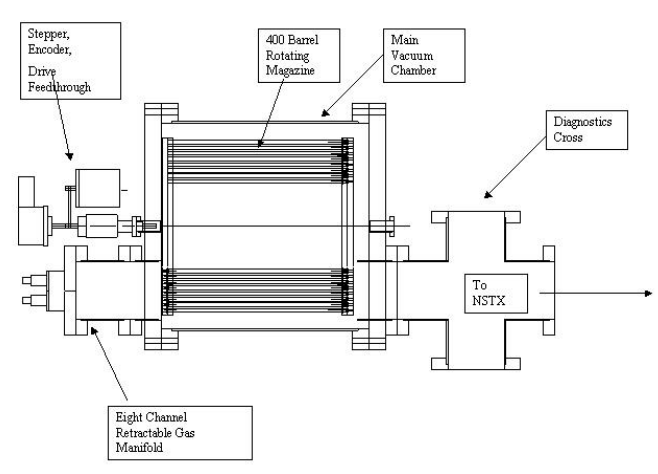

Figure 5. Complete Pellet Injector.

An eight-channel gas manifold aligns and engages with the selected zone of eight guide tubes motored to the firing position. Finally, a vacuum cross is provided in the flight path to the NSTX vacuum vessel for the inclusion of laser and piezoelectric diagnostics to allow velocity measurements and propellant gas control, if needed.

A well-considered control scheme has been devised by Princeton's computer and electrical engineering staff and described by Sichta, et al. [3]. A significant aspect of the control approach is the ability to quickly switch $(50 \mathrm{~ms} / \mathrm{switch})$ the valve driver between the eight Parker Series 9 gas admission valves mounted on the manifold. This capability will allow multiple pellet flights during a single plasma.

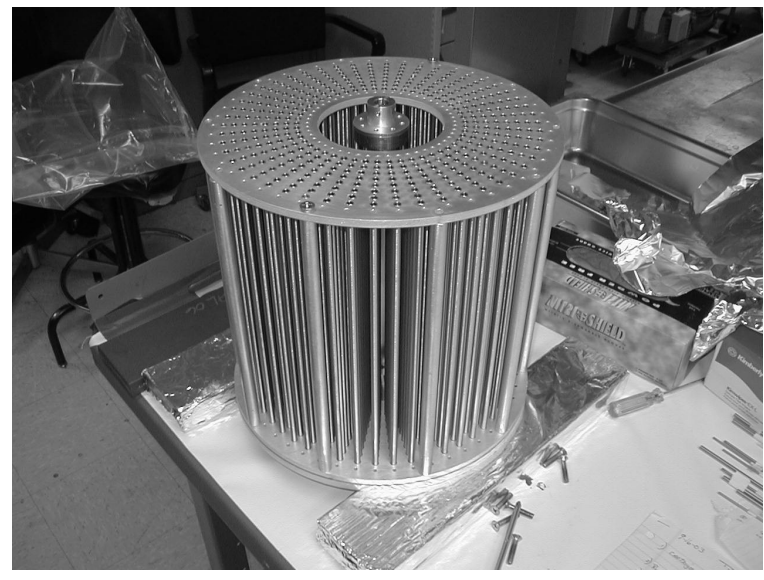

Figure 6. Magazine Subassembly.

Figure 6 shows the partially-assembled 400-tube magazine with the tube-ends exposed. Each end of the magazine has a 0.063 inch Viton sheet with 400 appropriately sized and located holes for isolating the guide tube bores (and propellant gas) from the vacuum system. This theme will be continued below.

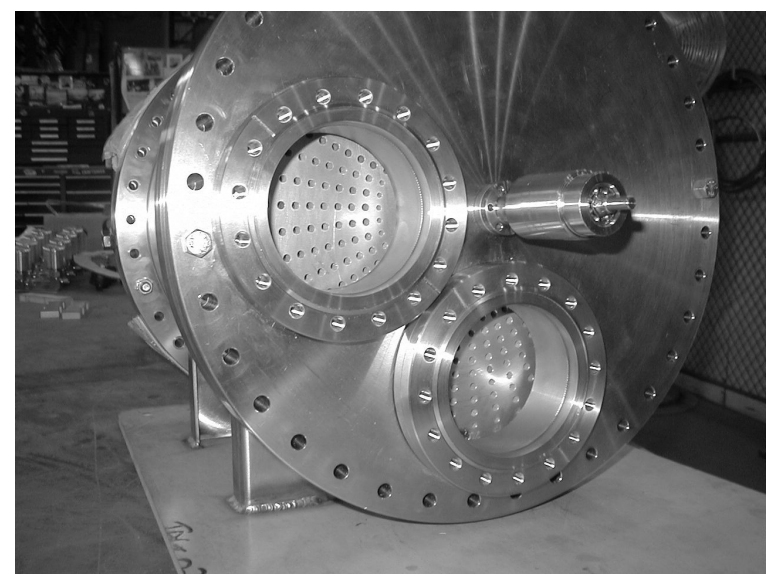

Figure 7. Magazine in Main Chamber.

Figure 7 shows the magazine mounted in the chamber. The 8-tube zone (one of 50 zones, total) centered in the low port receives the gas manifold assembly, shown in Figure 8. The gas manifold has eight Parker Series 9 gas admission valves mounted to it in a 2 high $\mathrm{x} 4$ wide rectangular array to allow for a magnetic shield enclosure (not shown). This $2 \mathrm{x}$ 4 array is converted to a 1 wide $\times 8$ high pattern having the spacing of the 8-tube magazine zone by means of a cross-milled plate that is vacuum brazed between a 6 inch Conflat flange and the $2 \times 4$ pattern adapter plate, both shown in Figures $9 a$ \& 9b. Note also in Figure 8 that an eight-channel Viton nose seal is fitted across the nose of the gas manifold assembly. 


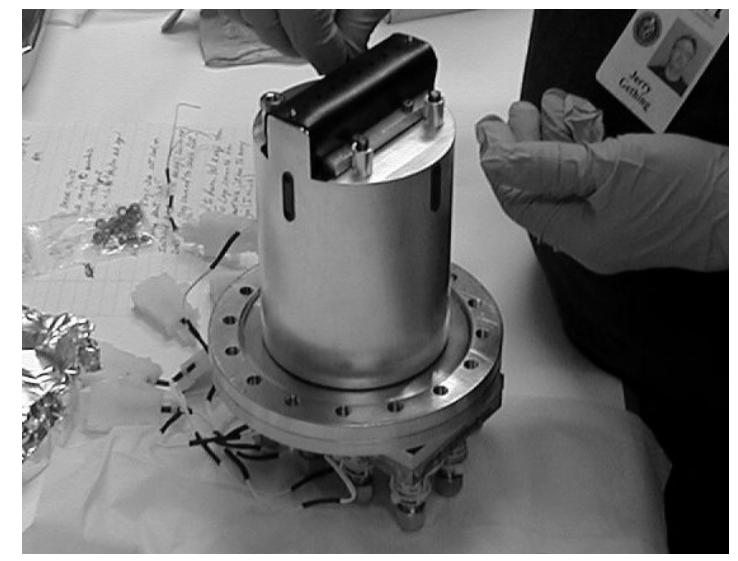

Figure 8. Gas Manifold Assembly.

This nose seal, along with the previously-mentioned Viton sheets included at the tube ends in the magazine assembly, establish propellant gas containment in effectively the same manner demonstrated with the prototype injector.
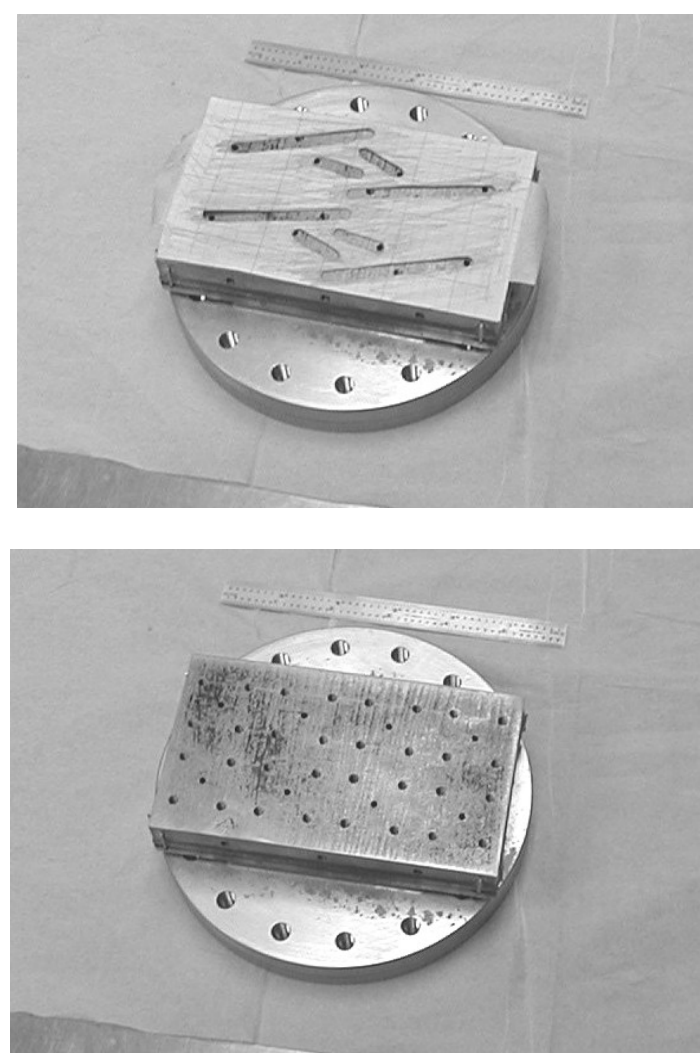

Figures 9a \& 9b. Cross-Milled Manifold Plate and Complete Brazed Assembly.

Figure 10 shows a partial assembly of the gas manifold inserted in the firing port of the main chamber. A vacuum bellows (not shown) seals the vacuum system and allows retraction of the gas

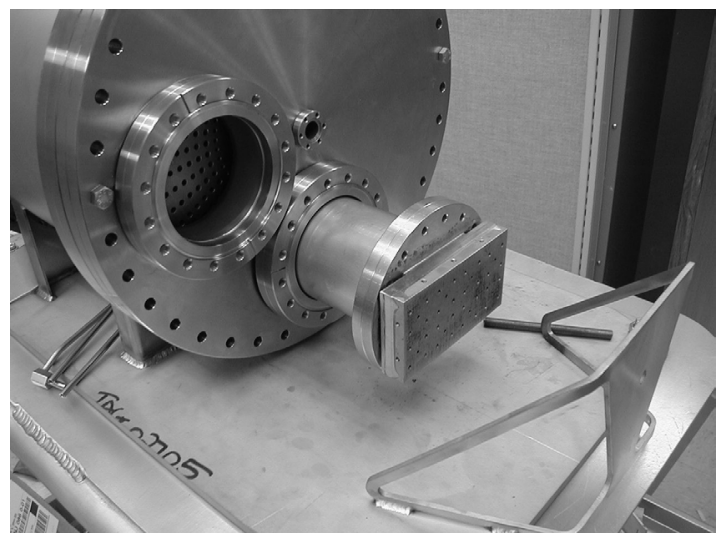

Figure 10. Partial Gas Manifold Place in Main Chamber (vacuum bellows omitted).

manifold assembly slightly to permit the rotation of the magazine to the next desired 8-tube zone.

\section{SUMMARY AND CONCLUSIONS}

The lithium and low-Z injector proposed for service on NSTX benefits from lessons learned in both cryo and ambient temperature pneumatic injectors built for the fusion community. The suitability of a cartridge-employing injector has been demonstrated in a prototype program and hardware and controls for a 400 tube injector are well under way. Injection into NSTX plasmas, with potential for as many as eight pellets per shot, is planned for the run period in $\mathrm{FY}{ }^{\prime} 04$.

\section{ACKNOWLEDGMENT}

This is work supported by U.S. DOE Contract DEAC02-76CH03073.

\section{REFERENCES}

[1] J. E. Menard, et al., "Beta-limiting MHD Instabilities in Improved Performance NSTX Spherical Torus Plasmas", Nucl. Fusion, 43 (2003) 330, and references therein.

[2] L. Garzotti, et al., "Noncryogenic Pellet Injector for Diagnostic Purposes on the RFX Reversed Field Pinch", Rev. Sci. Inst., 70 (1999) 939.

[3] P. Sichta, et al., "Control System for the NSTX Lithium Pellet Injector", in these proceedings. 


\section{External Distribution}

Plasma Research Laboratory, Australian National University, Australia

Professor I.R. Jones, Flinders University, Australia

Professor João Canalle, Instituto de Fisica DEQ/IF - UERJ, Brazil

Mr. Gerson O. Ludwig, Instituto Nacional de Pesquisas, Brazil

Dr. P.H. Sakanaka, Instituto Fisica, Brazil

The Librarian, Culham Laboratory, England

Mrs. S.A. Hutchinson, JET Library, England

Professor M.N. Bussac, Ecole Polytechnique, France

Librarian, Max-Planck-Institut für Plasmaphysik, Germany

Jolan Moldvai, Reports Library, Hungarian Academy of Sciences, Central Research Institute for Physics, Hungary

Dr. P. Kaw, Institute for Plasma Research, India

Ms. P.J. Pathak, Librarian, Institute for Plasma Research, India

Ms. Clelia De Palo, Associazione EURATOM-ENEA, Italy

Dr. G. Grosso, Instituto di Fisica del Plasma, Italy

Librarian, Naka Fusion Research Establishment, JAERI, Japan

Library, Laboratory for Complex Energy Processes, Institute for Advanced Study, Kyoto University, Japan

Research Information Center, National Institute for Fusion Science, Japan

Dr. O. Mitarai, Kyushu Tokai University, Japan

Dr. Jiangang Li, Institute of Plasma Physics, Chinese Academy of Sciences, People's Republic of China

Professor Yuping Huo, School of Physical Science and Technology, People's Republic of China

Library, Academia Sinica, Institute of Plasma Physics, People's Republic of China

Librarian, Institute of Physics, Chinese Academy of Sciences, People's Republic of China

Dr. S. Mirnov, TRINITI, Troitsk, Russian Federation, Russia

Dr. V.S. Strelkov, Kurchatov Institute, Russian Federation, Russia

Professor Peter Lukac, Katedra Fyziky Plazmy MFF UK, Mlynska dolina F-2, Komenskeho Univerzita, SK-842 15 Bratislava, Slovakia

Dr. G.S. Lee, Korea Basic Science Institute, South Korea

Institute for Plasma Research, University of Maryland, USA

Librarian, Fusion Energy Division, Oak Ridge National Laboratory, USA

Librarian, Institute of Fusion Studies, University of Texas, USA

Librarian, Magnetic Fusion Program, Lawrence Livermore National Laboratory, USA

Library, General Atomics, USA

Plasma Physics Group, Fusion Energy Research Program, University of California at San Diego, USA

Plasma Physics Library, Columbia University, USA

Alkesh Punjabi, Center for Fusion Research and Training, Hampton University, USA

Dr. W.M. Stacey, Fusion Research Center, Georgia Institute of Technology, USA

Dr. John Willis, U.S. Department of Energy, Office of Fusion Energy Sciences, USA

Mr. Paul H. Wright, Indianapolis, Indiana, USA 
The Princeton Plasma Physics Laboratory is operated by Princeton University under contract with the U.S. Department of Energy.

\author{
Information Services \\ Princeton Plasma Physics Laboratory \\ P.O. Box 451 \\ Princeton, NJ 08543
}

Phone: 609-243-2750

Fax: 609-243-2751

e-mail: pppl_info@pppl.gov

Internet Address: http://www.pppl.gov 